\title{
The Expression of T Cell FOXP3 and T-Bet Is Upregulated in Severe but Not Euthyroid Hashimoto's Thyroiditis
}

\author{
Stana Tokić, ${ }^{1,2,3}$ Mario Štefanić, ${ }^{2,4}$ Ljubica Glavaš-Obrovac, ${ }^{2}$ \\ Sonja Jaman, ${ }^{1}$ Eva Novosadová, ${ }^{3}$ Jana Petrkova, ${ }^{3}$ Zdenka Navratilova, ${ }^{3}$ \\ Mirjana Suver Stević, ${ }^{1}$ and Martin Petrek ${ }^{3}$ \\ ${ }^{1}$ Department of Molecular Diagnostics and Tissue Typing, Osijek University Hospital, Josipa Huttlera 4, 31000 Osijek, Croatia \\ ${ }^{2}$ Faculty of Medicine, University of Osijek, Cara Hadrijana 10E, 31000 Osijek, Croatia \\ ${ }^{3}$ Laboratory of Immunogenomics, Department of Pathological Physiology, Faculty of Medicine and Dentistry, \\ Palacký University, 77520 Olomouc, Czech Republic \\ ${ }^{4}$ Clinical Institute of Nuclear Medicine and Radiation Protection, Osijek University Hospital, Josipa Huttlera 4, 31000 Osijek, Croatia
}

Correspondence should be addressed to Stana Tokić; tokic.stana@kbo.hr

Received 9 February 2016; Revised 20 May 2016; Accepted 1 June 2016

Academic Editor: Anshu Agrawal

Copyright (c) 2016 Stana Tokić et al. This is an open access article distributed under the Creative Commons Attribution License, which permits unrestricted use, distribution, and reproduction in any medium, provided the original work is properly cited.

\begin{abstract}
Hashimoto's thyroiditis (HT) is an organ-specific autoimmune disorder characterized by progressive thyroid failure. Th1 and Treg subset of $\mathrm{CD}^{+}$cells have been implicated in the pathogenesis; however, less is known about their respective roles across the spectrum of HT clinical presentations. To shed more light on $\mathrm{CD}^{+}$subsets role in $\mathrm{HT}$, we investigated the mRNA expression levels of several Th1/Treg-associated transcription factors (T-bet/ETS1, HIF1 $\alpha /$ BLIMP1/FOXP3) in peripheral blood T cells of 10 hypothyroid, untreated HT patients, 10 hypothyroid patients undergoing hormone replacement therapy, 12 euthyroid HT subjects, and 11 healthy controls by the qRT-PCR. Compared to euthyroid HT patients and controls, both hypothyroid (2.34-fold difference versus controls, $P<0.01)$ and thyroxine-supplemented patients $(2.5$-fold, $P<0.001)$ showed an increased FOXP3 mRNA expression in T cells. Similarly, mRNA expression levels of T-bet were upregulated in severely affected but not in euthyroid HT subjects (2.37-fold and 3.2-fold, hypothyroid and thyroxine-supplemented HT patients versus controls, resp., $P<0.01$ ). By contrast, no differences in mRNA expression levels of ETS1, BLIMP1, and HIF1 $\alpha$ were observed across the study groups. In summary, severe but not euthyroid HT was associated with robust upregulation of T-bet and FOXP3 mRNA in peripheral T cells, independent of the thyroid hormone status but proportional to disease activity.
\end{abstract}

\section{Introduction}

Hashimoto's thyroiditis (HT) is the second most widespread endocrine disorder characterized by autoimmune thyroid destruction and subsequently hypothyroidism. Traditionally, the pathogenesis of HT has been characterized by thyroid homing of autoreactive T-helpers 1 (Th1), cytotoxic Tlymphocytes, and NK cells, all of which are involved in targeted killing of thyroid follicular cells through antibodymediated cytotoxicity and apoptosis [1].

Recently, two new subsets of Th cells, Th17, and regulatory $\mathrm{T}$ (Treg) cells have been implicated in HT pathogenesis [2-8]. Consequently, the imbalance between Th1, Th17, and
$\mathrm{CD} 4^{+} \mathrm{CD} 25^{+}$Treg cells has been associated with thyroid inflammation [3-8], disease severity [6-8], and HT destructiveness $[3,8]$.

Th1 and Treg cell polarization is driven by lineage-specific master regulators, encompassing transcription factors (TFs) such as T-bet and FOXP3. In addition, several noncanonical TFs have been recently recognised to affect differentiation and function of Th1/Treg cells. Among these, ETS1 is essential for mounting effective Th1 responses $[9,10]$ and maintenance of Treg suppressive function by upregulating FOXP3 [11]. By contrast, the transcriptional repressor BLIMP1 (encoded by the PRDM1 gene) is predominantly involved in attenuation of proinflammatory Thl and Thl7 responses through 
negative regulation of INF- $\gamma$, T-bet, and interleukin- (IL-) $2[12,13]$. In $\mathrm{CD} 4^{+}$Tregs, BLIMP1 is highly expressed and supports Treg suppressive function by upregulating IL10 [14]. Finally, a novel Treg/Th17 TF, hypoxia inducible factor (HIF) $1 \alpha$, has been proven essential factor for Th17 differentiation by skewing Treg polarization through FOXP3 destabilization and cooperative action with ROR $\gamma \mathrm{t}$ [15]. However, the importance of these factors for the pathogenesis of HTs has been rarely addressed; moreover, most of the studies have considered HT singular phenotype regardless of the disease complexity, particularly given the differences in thyroid function across the clinical spectrum of disease.

To address the role of $\mathrm{T}$ cell TFs in HT, we determined Th1 (T-bet, ETS1) and Treg-associated (HIF1 $\alpha$, BLIMP1, and FOXP3) mRNAs in peripheral blood T cells of HT patients. To explore possible differential expression at different clinical endpoints, we performed subanalyses in disease subsets characterized by distinct stage and residual thyroid function.

\section{Materials and Methods}

2.1. Subjects. Blood samples from healthy volunteers and patients were obtained at the Clinical Institute of Nuclear Medicine and Radiation Protection, Osijek University Hospital, Osijek, Croatia. HT was diagnosed as previously described [16] and 32 patients were age-matched, sexmatched, and classified into three subgroups according to the thyroid hormone levels at the time of diagnosis. The study comprised (1) 12 spontaneously euthyroid HT patients (EU HT), (2) 10 hypothyroid, untreated patients (HYPO HT), and (3) 10 hypothyroid HT cases rendered euthyroid by thyroxine (L-T4) replacement therapy [HYPO SUBST, mean L-T4 dose $1.13 \mu \mathrm{g} / \mathrm{kg}$ body weight daily, median pretreatment serum thyrotropin (TSH) $15.1 \mathrm{mU} / \mathrm{L}$, and interquartile range 11.5-35.3 mU/L]. The median follow-up for the entire patient cohort was 7 (interquartile range 5-8) years.

The control group (CTRL) consisted of 11 randomly selected, healthy, euthyroid, thyroid peroxidase autoantibodies- (TPOAb-) negative individuals, with no evidence or family history of autoimmune and endocrine disorders. All control subjects had normal ultrasound findings of thyroid gland. All participants were unrelated adults from eastern Croatia. Informed consent in written form was obtained prior to the study and study protocol was reviewed and approved by the institutional ethical committee.

\subsection{Thyroid Function Measurement. TSH (normal range:} 0.46-4.7 mIU/L, Vitros TSH Reagent Pack), free triiodothyronine (FT3) (1.9-5.7 pmol/L, Vitros FT3 Reagent Pack), and free T4 (FT4, 10-22 pmol/L, Vitros FT4 Reagent Pack, all from Ortho-Clinical Diagnostics, Amersham, UK) were measured in morning serum samples, taken between 8 a.m. and 12 p.m., according to the manufacturer's instructions. Maximum pretreatment serum TPOAb-IgG (50-125 kIU/L) was measured by ELISA (Anti-TPO Kit, Milenia Biotec, Germany) calibrated against WHO reference MRC 66/387a. Hypothyroidism was defined as clinically significant when TSH was $>4.7 \mathrm{mU} / \mathrm{L}$ and FT4 was $<10 \mathrm{pmol} / \mathrm{L}$, but it was considered subclinical or latent if TSH was $>4.7 \mathrm{mU} / \mathrm{L}$ and FT4 > $10 \mathrm{pmol} / \mathrm{L}$.

2.3. Peripheral Blood Mononuclear Cells (PBMC) Isolation. PBMC were isolated from peripheral blood by density gradient centrifugation on Lymphoprep (Axis Shield, Oslo, Norway) as described by Böyum [17]. Briefly, heparinized blood samples were diluted $1: 1$ with $0.9 \% \mathrm{NaCl}$ and following application to the Lymphoprep centrifuged for $20 \mathrm{~min}$ at $1000 \times \mathrm{g}$. Fraction of total lymphocytes and monocytes was harvested and rinsed with saline and then pelleted by centrifugation for $10 \mathrm{~min}$ at $550 \times \mathrm{g}$. The procedure was repeated twice. Cells were resuspended in $1 \mathrm{~mL}$ of the isolation buffer (PBS without $\mathrm{Ca}^{2+}$ and $\mathrm{Mg}^{2+}$ with $0.1 \%$ BSA and $2 \mathrm{mM}$ EDTA) and counted after trypan-blue staining using the Bürker-Türk counting chambers.

2.4. Lymphocyte Subsets Separation. T-lymphocytes were separated from mononuclear cells by negative selection using untouched human $\mathrm{T}$ cells isolation kit, magnetic beads (depletion Dynabeads), DynaMag ${ }^{\mathrm{TM}}$ magnet, and antibody mix (Invitrogen, Paisley, UK). Briefly, PBMC $\left(1 \times 10^{7}\right)$ were incubated for $20 \mathrm{~min}$ at $2-8^{\circ} \mathrm{C}$ with heat inactivated fetal bovine serum and mouse monoclonal antibodies specific for CD14, CD16, CD19, CD36, CD56, CDw123, and CD235. After the incubation, cells were washed with the isolation buffer and pelleted by centrifugation at $300 \times \mathrm{g}$ for $8 \mathrm{~min}$. The pellet was resuspended and incubated for $15 \mathrm{~min}$ with prewashed magnetic beads, coated with monoclonal human anti-mouse IgG antibody. The bead-bound cells were subsequently separated on a DynaMag magnet, leaving cell suspension free from B-lymphocytes, NK cells, monocytes, platelets, dendritic cells, granulocytes, and erythrocytes. The remaining untouched $\mathrm{CD}^{+}$and $\mathrm{CD} 8^{+}$T-lymphocytes were transferred to a new tube. Steps involving washing and binding of bead-bound cells to a magnet were repeated twice. Residual Dynabeads were removed by placing the tube in a magnet for $2 \mathrm{~min}$ and then transferring the supernatant to a new tube.

2.5. Total RNA Extraction. Total RNA was extracted from untouched T-lymphocytes using TRI REAGENT (Sigma, USA) solution as described by Chomczynski and Sacchi [18]. Quality of total RNA was checked by ethidium bromide staining in $2 \%$ agarose gel electrophoresis and $\mathrm{OD}_{260} / \mathrm{OD}_{280}$ ratio $>1.8$ measurements by NanoDrop 1000 spectrophotometer (Thermo Fisher Scientific, USA). Out of 43 samples of total RNA, 9 samples (20.9\%) suspected for DNA contamination underwent DNase treatment using the Ambion ${ }^{\circledR}$ DNAfree $^{\mathrm{TM}}$ DNA Removal kit (Life Technologies, Carlsbad, USA) according to the manufacturer's instructions.

2.6. cDNA Synthesis. cDNA synthesis was performed using Transcriptor First Strand cDNA Synthesis Kit (Roche, Mannheim, Germany). For better coverage of the transcriptome, both anchored oligo-dT $(2.5 \mu \mathrm{M})$ and random hexamer primers $(60 \mu \mathrm{M})$ were added to $40 \mu \mathrm{L}$ master mix comprising $400 \mathrm{ng}$ of total RNA, dNTP mix ( $1 \mathrm{mM}$ each), $40 \mathrm{U}$ of RNase inhibitor, and $20 \mathrm{U}$ of reverse transcriptase. The run 
TABLE 1: List of TaqMan probes and amplicon sizes of investigated genes.

\begin{tabular}{|c|c|c|c|c|c|}
\hline Assay ID & Gene abbreviation & Gene name & $\begin{array}{c}\text { GenBank accession } \\
\text { number }\end{array}$ & Function & Amplicon size (bp) \\
\hline Hs00428293_ml & ETS1 & $\begin{array}{l}\text { Erythroblastosis virus E26 } \\
\text { oncogene homolog } 1 \\
\text { (avian) }\end{array}$ & NM_001143820.1 & $\begin{array}{l}\text { Transcription factor, } \\
\text { involved in mounting of } \\
\text { Th1 response and } \\
\text { inhibition of Th17 } \\
\text { development }\end{array}$ & 99 \\
\hline Hs01085834_ml & FOXP3 & Forkhead box P3 & NM_014009.3 & $\begin{array}{l}\text { Transcriptional regulator } \\
\text { of Treg cell development } \\
\text { and function }\end{array}$ & 61 \\
\hline Hs00153153_m1 & HIF1A & Hypoxia inducible factor 1 & NM_001530.3 & $\begin{array}{l}\text { Transcriptional } \\
\text { regulator, activator of } \\
\text { ROR- } \gamma \text { t expression and } \\
\text { Th17 differentiation }\end{array}$ & 76 \\
\hline Hs99999909_ml & HPRT1 & $\begin{array}{l}\text { Hypoxanthine } \\
\text { phosphoribosyltransferase } 1\end{array}$ & NM_000194.2 & Purine metabolism & 100 \\
\hline Hs00153357_m1 & PRDM1/BLIMP1 & $\begin{array}{l}\text { PR domain containing } 1 \text {, } \\
\text { with ZNF domain/B- } \\
\text { lymphocyte-induced } \\
\text { maturation protein } 1\end{array}$ & NM_001198.3 & $\begin{array}{l}\text { Repressor of } \\
\text { beta-interferon }(\beta \text {-IFN) } \\
\text { gene expression }\end{array}$ & 65 \\
\hline Hs00420895_gH & RPLP0 & $\begin{array}{l}\text { Ribosomal protein, large, } \\
\text { P0 }\end{array}$ & NM_001002.3 & $\begin{array}{l}\text { Ribosomal protein, } \\
\text { component of } 60 \mathrm{~S} \\
\text { subunit }\end{array}$ & 76 \\
\hline Hs00894392_ml & TBX21 & T-box 21 & NM_013351.1 & $\begin{array}{l}\text { T cell-specific T-box } \\
\text { transcription factor }\end{array}$ & 119 \\
\hline Hs99999910_m1 & ТPB & TATA box binding protein & NM_003194.4 & Transcription factor & 127 \\
\hline
\end{tabular}

protocol was set at $65^{\circ} \mathrm{C}$ for $10 \mathrm{~min}$ for initial denaturation of RNA/primer mix and, after adding cDNA synthesis mix, continued at $25^{\circ} \mathrm{C}$ for $10 \mathrm{~min}, 55^{\circ} \mathrm{C}$ for $60 \mathrm{~min}$, and $85^{\circ} \mathrm{C}$ for $5 \mathrm{~min}$. All cDNA samples were diluted 8 -fold to $1.25 \mathrm{ng} / \mu \mathrm{L}$ end-point concentrations and stored in aliquots at $-20^{\circ} \mathrm{C}$ until use.

2.7. Quantitative Real-Time PCR. The mRNA expression levels of five target (FOXP3, ETS1, TBX21, BLIMP1, and HIF $1 \alpha$ ) and three reference genes (TBP, HPRT1, and RPLPO) were measured by quantitative real-time polymerase chain reaction (qRT-PCR). The amplification of investigated transcripts was performed with the Rotor Gene 3000 instrument (Corbett Research, USA) in a $15 \mu \mathrm{L}$ total volume, containing $6.75 \mu \mathrm{L}$ of cDNA, $7.5 \mu \mathrm{L}$ of TaqMan Universal PCR Master Mix II kit, and $0.75 \mu \mathrm{L}$ of predeveloped individual TaqMan gene expression assay (Applied Biosystems). The cycling conditions were set according to the guidelines in the manufacturer's leaflet. The list of assays and amplicon sizes of the investigated genes is given in Table 1.

All qRT-PCR reactions were performed in triplicate and no-template negative control was included in each experiment. The reverse transcription negative controls without RT enzyme or template cDNA were run in parallel and did not yield any PCR product. At the end of each PCR run, realtime fluorescence measurements were collected at threshold cycle (Ct) defined as the fractional cycle number at which fluorescence passes fixed threshold of 0.05. Real-time PCR result was called an outlier at $\mathrm{SD}(\mathrm{Ct})>0.3$ and accordingly $9(0.7 \%)$ out of 1278 PCR reactions were excluded from further analyses. Intra-assay variability was less than $0.92 \%$ for all investigated transcripts and less than $1.21 \%$ between different PCR experiments. All data were exported to GenEx software, and NormFinder and geNorm algorithms were used for identification of the most stably expressed reference gene. Pairwise analysis performed in geNorm identified TBP and HPRT1 as the best gene pair nominated by identical values of stability measure $(\mathrm{M}=0.4922)$. TBP was selected as the most stable gene showing the lowest intra- $(\mathrm{SD} \pm 0.04)$ and intergroup $(S D \pm 0.12)$ variability. Finally, fold difference in mRNA levels in unknown samples versus controls was calculated in comparison to TBP endogenous control using efficiency corrected model of $\Delta \Delta \mathrm{Ct}$ relative quantification method as described by Pfaffl 2001 [19].

2.8. Statistical Analysis. Data are presented as arithmetic means \pm standard deviations (SD) or medians with interquartile ranges (IQR) where applicable. Kruskal-Wallis test with Bonferroni-modified Dunn's post hoc analysis was used for group comparisons. Pairwise correlations were determined by Spearman rank test. Two-tailed $P<0.05$ was considered significant. If not otherwise stated, all statistical analyses were performed with NCSS2007 v07.1.20, NCSS LLC., Kaysville, USA. 
TABLE 2: Descriptive analysis of clinical and biochemical characteristics of patients and healthy controls.

\begin{tabular}{lcccc}
\hline & HYPO HT & SUBST HT & EU HT & CTRL \\
\hline Subjects & 10 & 10 & 12 & 11 \\
Age & $42.3 \pm 4.62$ & $57.7 \pm 4.62$ & $50.6 \pm 4.22$ & $45 \pm 4.41$ \\
Gender (F/M) & $8 / 2$ & $9 / 1$ & $12 / 0$ & $10 / 1$ \\
FT4 $(\mathrm{pmol} / \mathrm{L})$ & $11.01 \pm 0.83$ & $16.31 \pm 0.83^{*}$ & $12.12 \pm 0.76$ & $14.09 \pm 0.8^{* *}$ \\
FT3 $(\mathrm{pmol} / \mathrm{L})$ & $2.91 \pm 0.27$ & $3.38 \pm 0.27$ & $3.24 \pm 0.24$ & $3.6 \pm 0.25$ \\
TSH $(\mathrm{mIU} / \mathrm{L})$ & $10.35(5.25-13.1)$ & $2.59(0.9-3.0)^{\#}$ & $3.11(1.6-4.3)$ & $1.63(1.0-2.4)^{\# \#}$ \\
TPOAb $(\mathrm{kIU} / \mathrm{mL})$ & $155(61-2217)$ & $246(77-969)$ & $677(267-1112)$ & $\mathrm{neg}$ \\
\hline
\end{tabular}

Data are presented as mean \pm SD or median with interquartile range (25th-75th percentile) according to the distribution. The study included 11 healthy controls (CTRL) and 32 HT patients classified as hypothyroid (HYPO HT), rendered euthyroid by thyroxine (L-T4) replacement therapy (SUBST HT), and spontaneously euthyroid (EU HT).

F: female and M: male. The $P$ value represents different groups compared with hypothyroid HT patients.

${ }^{*} P=0.00006 ;{ }^{* *} P=0.01 ;{ }^{\#} P=0.1 \times 10^{-5} ;{ }^{\# \#} P=0.1 \times 10^{-6}$ (Kruskal-Wallis test and Bonferroni-Dunn's post hoc comparison).

FT4: free thyroxine (normal range: $10-22 \mathrm{pmol} / \mathrm{L}$ ); FT3: free triiodothyronine (1.9-5.7 pmol/L); TSH: thyroid stimulating hormone (normal range: $0.46-$ $4.7 \mathrm{mIU} / \mathrm{L})$.

\section{Results}

3.1. Subject Characteristics. Biochemical and demographical data are presented in Table 2. No differences in sex composition were found among the groups and no difference in serum FT3 and TSH values was seen between healthy controls and euthyroid and L-T4 substituted HT patients. Generally, higher FT4 levels were required to match the FT3 values in controls, most likely reflecting both morning intake of L-T4 shortly before blood collection and a trend for lower FT3 in L-T4 treated HT patients. As expected, FT4 serum levels were reduced and TSH levels significantly increased in hypothyroid patients when compared to the controls and LT4 substituted subjects.

3.2. Expression Profiles of Investigated Th1-Associated Transcription Factors. Regarding expression of Th1 regulators, T-bet was upregulated in peripheral $\mathrm{T}$ cells isolated from hypothyroid, both untreated [median fold change 2.37, IQR (2.0-2.8), and $P<0.01]$ and thyroxine-supplemented patients [3.2-fold (2.13-3.85), $P<0.001$ ], but not in spontaneously euthyroid HT group [1.66-fold (1.4-2.0), $P>$ $0.05]$ or healthy controls [0.93-fold (0.56-1.26)] (Figure 1(a)). No difference in T-bet mRNA levels was observed between the treated and untreated hypothyroid patients with severe HT. Similarly, no significant difference was observed between euthyroid HT patients and healthy controls. Further, ETS1 mRNA levels were not different when compared across HT stages [HYPO HT, SUBST HT, and EU HT; 1.32 (1.04-1.64), 1.12 (0.97-1.41), and $1.12(0.86-1.22)$, resp., $P>0.05$ for all] or healthy controls [0.97 (0.87-1.33)] (Figure 1(b)).

3.3. Expression Profiles of Treg-Associated Regulators. Concerning Treg regulatory molecules, FOXP3 mRNA levels closely mirrored T-bet expression in untreated and thyroxine-supplemented patients (global $P=6.03 \times 10^{-4}$ ), showing 2.34-fold (1.83-2.96) and 2.5-fold (1.95-3.52) increment in median expression values when compared to the healthy controls, respectively (Figure $1(\mathrm{c})$ ). No difference between hypothyroid patients, treated and untreated (2.34fold versus 2.5 -fold, $P>0.05$ ), or between spontaneously euthyroid HT subjects and controls was observed (1.63-fold versus 1.09-fold, $P>0.05$ ). No changes across the studied groups [HYPO HT, SUBST HT, EU HT, and CTRL] were observed when BLIMP1 [1.37 (0.93-1.55); 1.57 (1.18-2.03); 1.08 (0.87-1.32); 1.06 (0.72-1.49), resp., $P>0.05$ for all, Figure 1(d)] or HIFl $\alpha$ transcripts were measured [1.35 (1.11.84); 1.04 (0.76-1.15); 1.09 (0.92-1.18); 0.98 (0.91-1.05), resp., $P>0.05$ for all, Figure 1(e)].

3.4. Correlation Analysis. To examine if there is any relationship between mRNA levels of Th1/Treg cell-associated regulators in peripheral $\mathrm{T}$ cells, we performed pairwise correlation analysis on pooled samples. A number of significant relationships were observed, as revealed by Spearman rank test (Figure 2).

Accordingly, elevated FOXP3 mRNA levels consistently coincided with mRNA levels of T-bet (Spearman's rho, $\rho=$ $0.56, P=0.0001$, Figure 2(a)) and ETS1 $(\rho=0.52, P<0.001$, Figure 2(b)). In line, T-bet and ETS1 were also positively related $(\rho=0.52, P<0.001$, Figure $2(\mathrm{c}))$. Additionally, increased T-bet expression was positively and independently correlated with BLIMP1 mRNA abundance ( $\rho=0.63, P<$ 0.0001 , Figure 2(d)).

A possible association between mRNA expression profile, age, and thyroid hormone levels was also investigated. Among the studied genes, FOXP3 mRNA levels were negatively associated with FT3 $(\rho=-0.44, P=0.0035)$ whereas ETS1 levels were weakly, albeit significantly negatively, correlated with FT4 levels ( $\rho=-0.35, P=0.027$ ). Additionally, a positive relationship was observed between age and BLIMP1 mRNA levels $(\rho=0.45, P=0.0024)$. After correction for multiple comparisons (Bonferroni corrected $P<0.0018$ ), these relationships did not attain significance (data not shown).

\section{Discussion}

In the present study, increased mRNA expression of T-bet, a master regulator of the Thl lineage, was observed in severely affected, hypothyroid patients, both treated and untreated, 


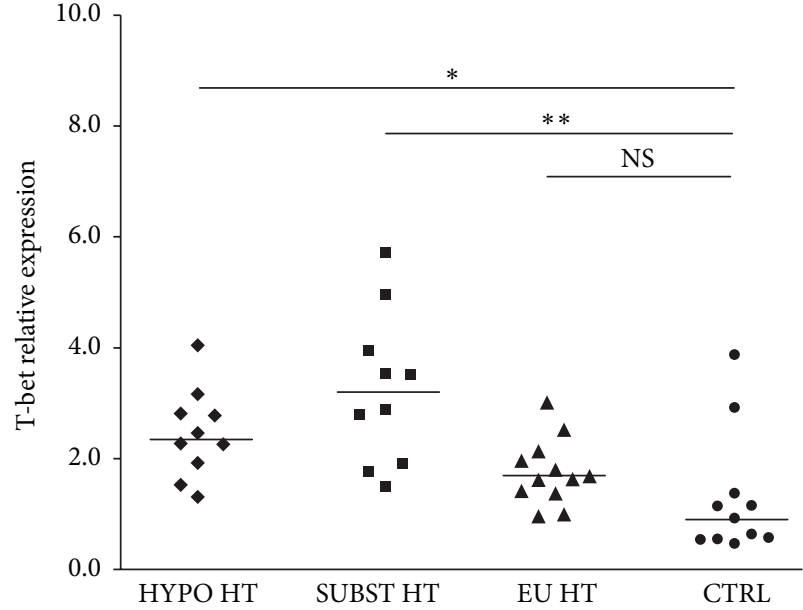

(a)

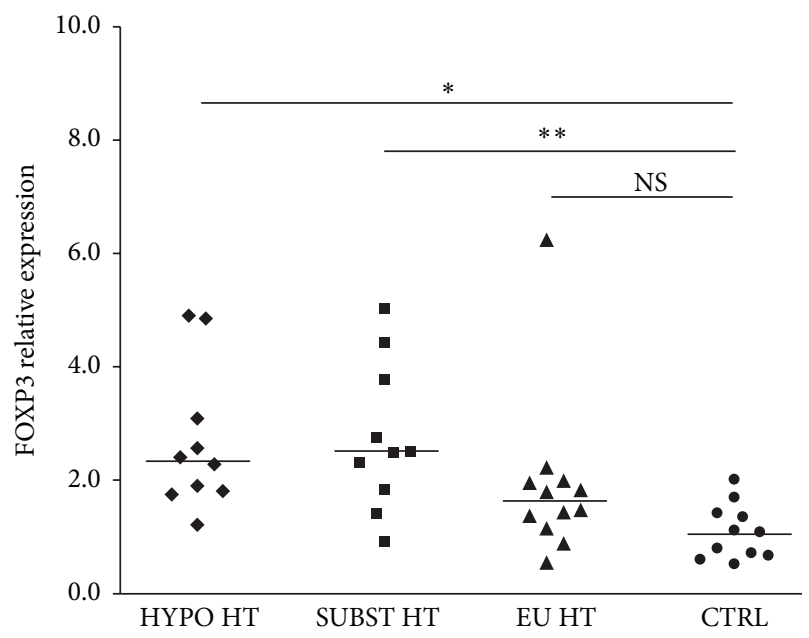

(c)

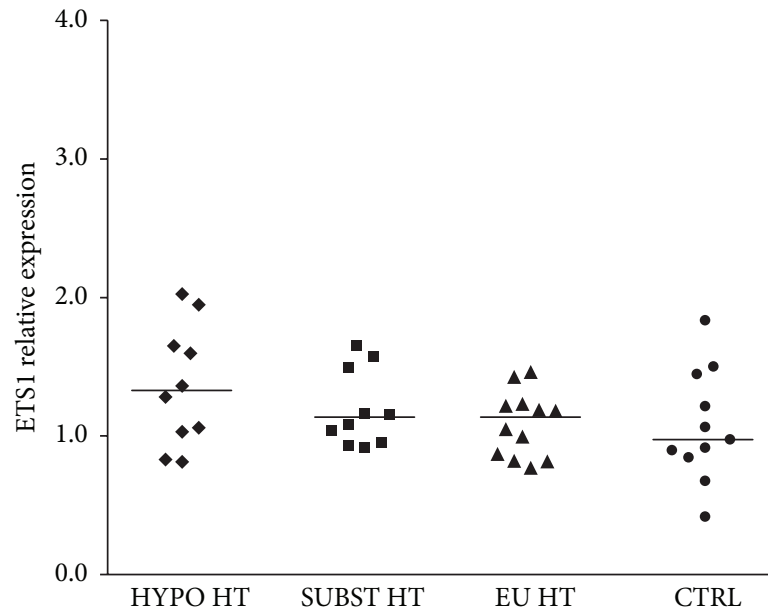

(b)

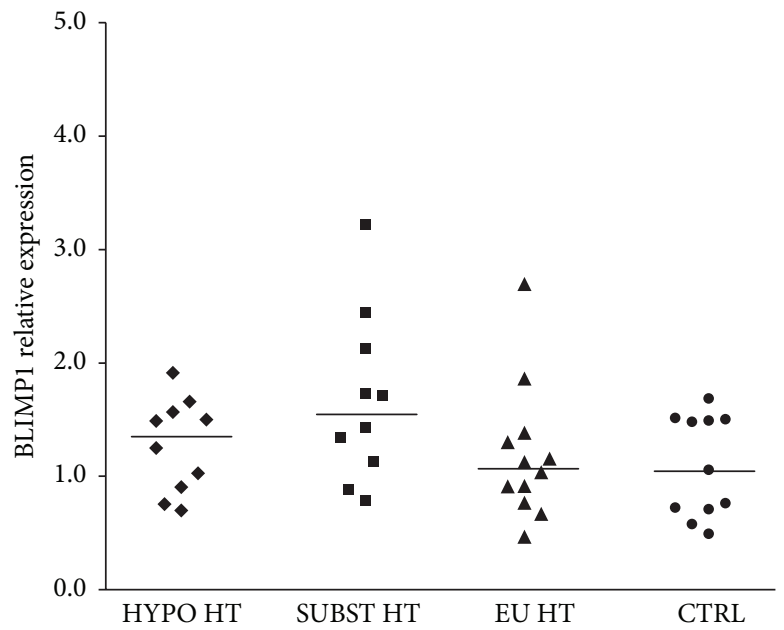

(d)

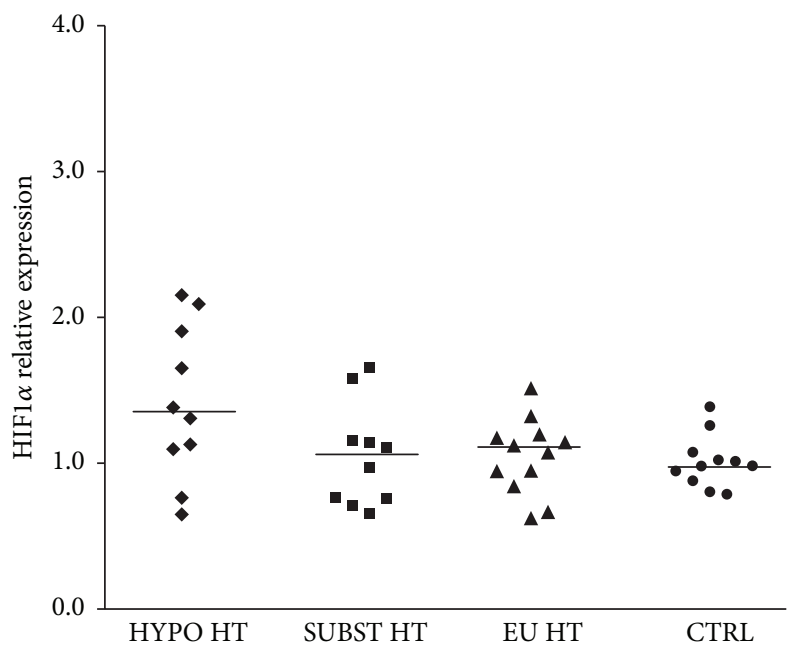

(e)

Figure 1: Relative mRNA levels of Th1/Treg-associated TF in HT patients and healthy controls. Compared to healthy controls (CTRL), (a) Tbet and (c) FOXP3 mRNA levels were upregulated in hypothyroid, both untreated (HYPO HT, ${ }^{*} \mathrm{P}<0.01$, Kruskal-Wallis test and BonferroniDunn's post hoc comparison) and thyroxine-supplemented (SUBST HT, ${ }^{* *} P<0.001$ ) patients but not in spontaneously euthyroid HT (EU HT) subjects. Conversely, differences in T-bet and FOXP3 mRNA levels, compared between HYPO HT and SUBST HT or between EU HT and CTRL subgroups, were not significant ( $P>0.05$ for all). Similarly, no difference was found in (b) ETS1, (d) BLIMP1, or (e) HIF1 $\alpha$ mRNAs levels across the studied groups. 


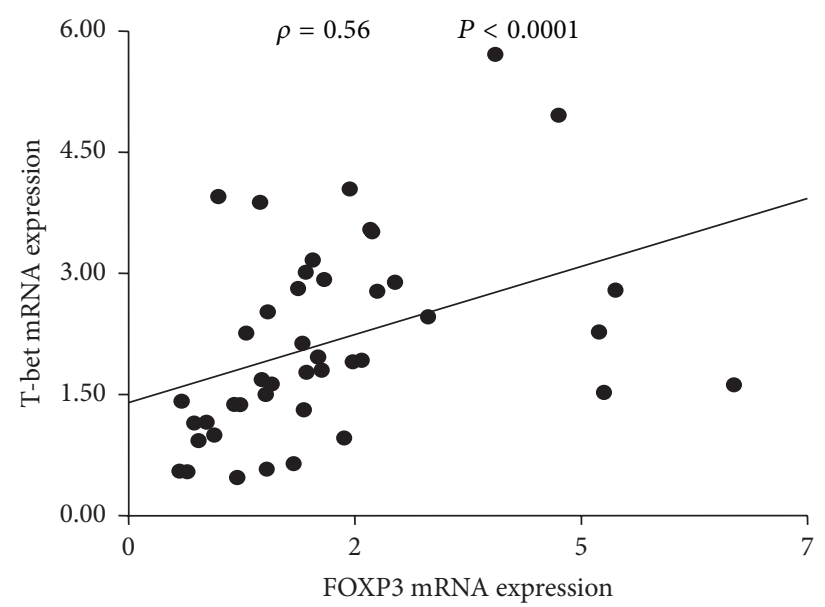

(a)

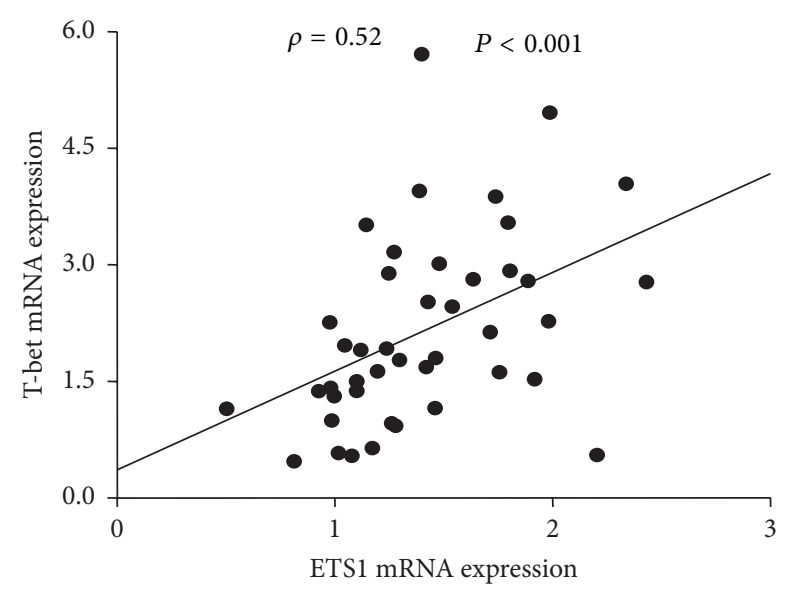

(c)

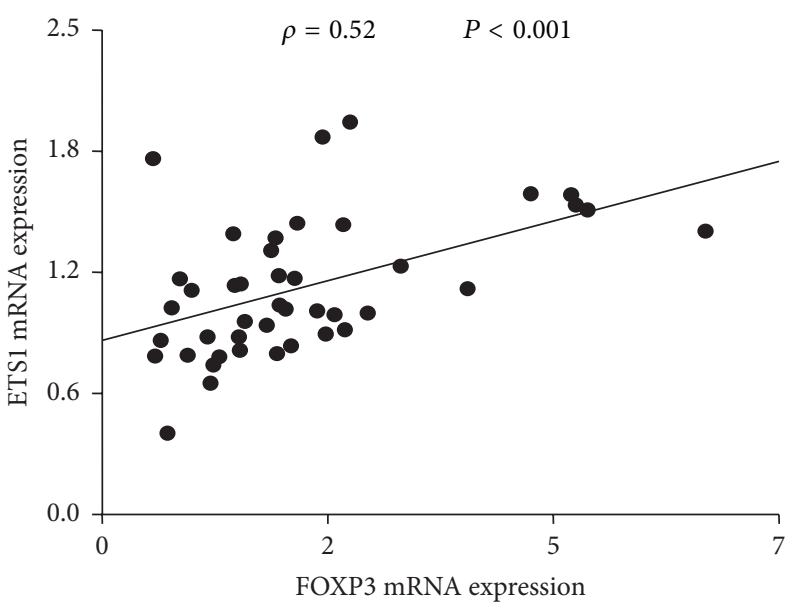

(b)

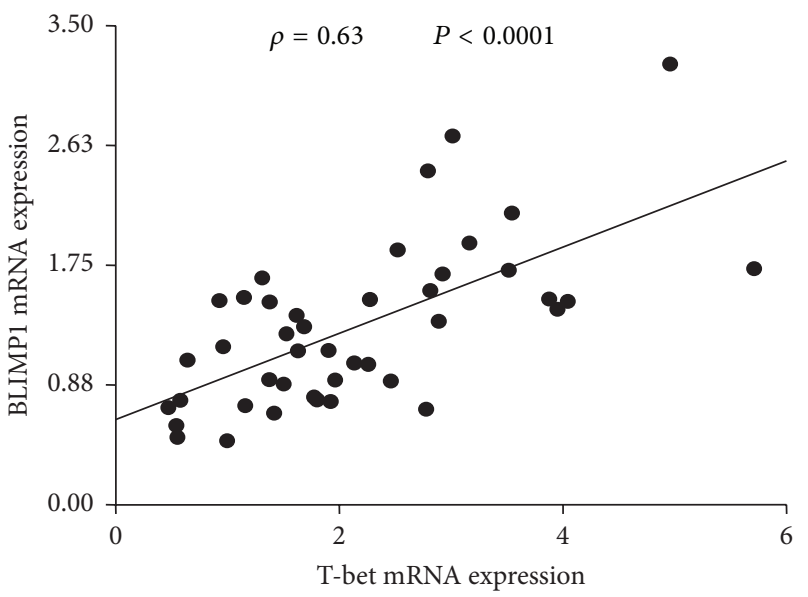

(d)

FIgURE 2: Spearman pairwise correlation analysis of T-bet, ETS1, FOXP3, BLIMP1, and HIF1 $\alpha$ mRNA levels in pooled samples $(n=43)$. FOXP3 positively correlated with (a) T-bet and (b) ETS1. T-bet was related to (c) ETS1 and (d) BLIMP1. $\rho$ : Spearman correlation coefficient; global significance $P<0.05$.

but not in spontaneously euthyroid HT counterparts; in addition, the prototypical Treg FOXP3 message closely mirrored T-bet expression patterns in both HT stages. Taken together, the findings suggest a simultaneous deregulation of T-bet ${ }^{+} \mathrm{Th} 1 / \mathrm{CD}^{+}$and $\mathrm{FOXP}^{+}{ }^{+}$Treg cell compartments in destructive, full blown HT, which seems to be less pronounced or absent in milder, euthyroid forms of the disease. Thus, distinct mechanisms may be engaged to different extent across the spectrum of thyroid autoimmunity, providing a solid basis for different therapeutical targets in HT.

Thyroid demission in HT is a multistep process, probably involving an individually variable set of mediators before a measurable effect develops. Thl cells are critical $\mathrm{T}$ effectors (Teff) in the pathogenesis of spontaneous autoimmune thyroiditis in iodine-treated NOD-H2h4 mice $[2,20]$, and the proportion of peripheral Thl cells is higher in patients with severe HT than in patients with mild HT [6]. T-bet is a direct transcriptional regulator of Th1 cytokines [21], commonly prevalent in both thyroid and PBMC of HT patients [22], and previously related to high TPOAb titres [23], disruption of thyroxisomes [24, 25] and apoptosis of thyroid follicular cells during in vitro induction of destructive autoimmune thyroiditis [26]. Accordingly, development of more destructive disease forms in HT seems to be driven by Th1 upregulation, and indeed we have recorded disease stage-dependent increment in T-bet mRNA levels in patients with severe HT. In contrast, $\mathrm{FOXP}^{+}$Treg lymphocytes play a nonredundant role in the protection against thyroid autoimmunity, as Treg depletion was shown to induce a Th1-dependent form of EAT in mice [20], while diminished Treg cell numbers and attenuated FOXP3 gene expression were found in PBMC of HT patients [7, 8]. Nevertheless, the existence of a functional rather than "numerical" deficiency in Treg cells has also been suggested in HT. In a single AITD study, a nonspecific defect in Treg regulatory function was observed in vitro, despite increased numbers of $\mathrm{FOXP}^{+} \mathrm{CD}^{+} 9^{+} \mathrm{CD} 4^{+} \mathrm{T}$ cells in both thyroid and PBMC of patients with AITD [27]. In yet another study, an elevated baseline production of mRNA encoding FOXP3 $\Delta 2$, an exon 2 splicing variant central to the glycolytic control of suppressive Tregs [28], was observed [29]. 
Despite the peripheral enrichment of $\mathrm{FOXP}^{+}{ }^{+} \mathrm{T}$ cells in our severe HT patients, thyroid inflammation is obviously still not suppressed, thus supporting the concept of a profound insufficiency of $\mathrm{CD}^{+} \mathrm{FOXP}^{+}$Treg cells in autoimmunity, previously also reported in rheumatoid arthritis [30], inflammatory bowel disease [31], and Graves' disease [27]. Underlying molecular mechanisms are currently controversially discussed: Treg suppressive capacity might be diminished by ligation of Treg expressed GITR (glucocorticoidinduced tumor necrosis factor receptor) by GITRL found in serum and inflamed thyroid tissue [7, 27]; once in the target organ intrathyroidal Tregs might suffer from apoptosisinduced decrease [32], or responder $\mathrm{T}$ effector cells may show resistance to Treg-mediated suppression due to the predominance of proinflammatory cytokines in the microenvironment, a mechanism previously demonstrated in vitro [33] and in vivo [34].

Alternatively, of interest is the possible transition of Treg lymphocytes towards proinflammatory Th17 cells, a phenomenon that may further contribute to the perpetuation of the autoimmune process. Indeed, Tregs may rapidly transdifferentiate towards Th17 phenotype [35] when exposed to cytokine milieu enriched with IL-6, IL-17, and IL-23 [36]. Such Th17 differentiation cues were previously reported in serum and thyroid tissue of HT patients $[3-5,22]$ and associated with loss of Teff/Treg cell balance and progression towards severe hypothyroidism $[7,8]$.

Finally, there is accumulating evidence that $\mathrm{CD} 4^{+} \mathrm{CD} 25^{+} \mathrm{FOXP}^{+}$Treg cells are heterogeneous in their commitment stages and expression of effector molecules of suppression [37]. This functional diversity of Treg cells is driven by specific TFs distinct from FOXP3, which coordinate a phenotypic and functional specialization of Th and Treg cells in parallel during different types of inflammatory response. Among these, T-bet is expressed by a subset of Treg cells [38] and is required for Tregs to suppress Th1 inflammatory responses [39]. Consequently, a proportionate relationship of $\mathrm{FOXP}^{+}$Treg cell frequency with generalized $\mathrm{T}$ cell activation and Th1 magnitude has been observed in vivo [40]. Thus, experimental differences aside, Treg homeostasis may be far more complex in AITD than currently appreciated and further work is required for understanding how different Treg subsets and their diverse functional properties are controlled in vivo [41].

In activated Tregs, evolutionarily conserved noncoding sequences located in the FOXP3 intronic regions, CNS2, help protect FOXP3 expression from destabilizing cytokine conditions [42] in an inflammatory environment. A number of TFs, including, but not limited to, ETS1 and FOXP3 itself can interact with CNS2, whereas the expression of other TFs such as T-bet [38], BLIMP1 [14], and HIF1 $\alpha$ in Tregs can also affect specific aspects of Treg functions [15]. Among these, HIF1 $\alpha$ suppresses Treg development by binding FOXP3 and targeting it for proteasomal degradation [15]; T cell-specific BLIMP1 deficiency exacerbates autoimmune pathology by increasing the ratio of Teff (Th1 and Th17) to Tregs [43], while ETS1 deficiency severely impairs the differentiation and function of both Th1 and Treg, but not Th17 cells [9, 11, 44]. A number of putative correlations observed between TFs in our study are broadly consistent with these presented knockout data.

Nevertheless, a question remains about the exact source of these mRNAs. T-bet is broadly, albeit not exclusively, expressed in human $\mathrm{CD} 4^{+} \mathrm{Th} 1$, cytotoxic, and memory $\mathrm{CD} 8^{+}$ $\mathrm{T}$ cells. FOXP3 is the master regulator of the $\mathrm{CD}^{+}{ }^{+}$Treg gene expression program, playing also a less clear role in $\mathrm{CD}^{+} \mathrm{FOXP}^{+}$Treg cells. Moreover, ETS1, BLIMP1, and HIFl $\alpha$ TFs are differentially engaged in multiple signalling pathways in $\mathrm{CD}^{+}$and $\mathrm{CD}^{+}$committed $\mathrm{T}$ cells and are alternatively expressed with respect to cell lineage, developmental stage, and function $[9,15,43-46]$, all of which may be responsible for observed mRNA data. Although no decisive role could be ascribed under the current experimental conditions, the limitations of the current study warrant further research into their roles in HT. Hence, several restrictions should be emphasized. (I) No cell sorting was performed and no protein level data were obtained. (II) Western blot should be used for analysis of HIF $1 \alpha$ protein levels. (III) The precise contribution in $\mathrm{CD}^{+}$versus $\mathrm{CD}^{+} \mathrm{T}$ cells or in naïve versus Teff cells was not investigated. No functional studies of different $\mathrm{T}$ cell subsets were performed and little information from affected tissues is available. The study could be significantly improved by both the inclusion of thyroid tissue samples and the analysis of expression of additional Th17/Treg cytokines and master regulators. (IV) The relatively small sample size is an additional limitation to optimal sensitivity; thus, the cohort was exploratory in nature. Nevertheless, strict selection criteria were applied, resulting in a well-characterized cohort regarding demographics, treatment exposures, thyroid residual function, and disease status. This stratification is crucial in pursuit for pathogenetic components in HT and may be an explanation for contradictory results in several similarly sized but phenotypically mixed studies. Finally, majority of patients in this study were female whites of European ancestry, thus limiting additional effects of sex or ethnicity.

In conclusion, our data provide preliminary evidence that change from mild to severe HT types is encouraged by parallel alterations in $\mathrm{T}^{- \text {bet }^{+}}$and $\mathrm{FOXP}^{+} \mathrm{T}$ cell compartments, independent of reductions in thyroid hormone levels, but proportional to disease stage. Even though underlying mechanisms remain beyond the competence of this study, our findings warrant further research into $\mathrm{FOXP}^{+} \mathrm{T}-$ bet $^{+} \mathrm{T}$ cell compartment in HT and may contain relevant investigation targets that will accelerate our understanding of Treg insufficiency in autoimmunity. However, further work is necessary for accurate dissection of the functional and numerical differences between $\mathrm{FOXP}^{+}{ }^{+}$and $\mathrm{T}_{\text {-bet }}{ }^{+} \mathrm{T}$ cell subsets of HT patients observed in this study.

\section{Competing Interests}

The authors declare that they have no competing interests.

\section{Acknowledgments}

This work was supported by the Palacky University (IGA PU LF 2015_020, 2016_009), Croatian Ministry of Science, 
Education and Sports (219-2190372-2068), and Josip Juraj Strossmayer University of Osijek (VIF-MEFOS-16, VIF2015MEFOS-2).

\section{References}

[1] G. Stassi and R. De Maria, "Autoimmune thyroid disease: new models of cell death in autoimmunity" Nature Reviews Immunology, vol. 2, no. 3, pp. 195-204, 2002.

[2] I. Horie, N. Abiru, Y. Nagayama et al., "T helper type 17 immune response plays an indispensable role for development of iodineinduced autoimmune thyroiditis in nonobese diabetic- $\mathrm{H} 2 \mathrm{~h} 4$ mice," Endocrinology, vol. 150, no. 11, pp. 5135-5142, 2009.

[3] N. Figueroa-Vega, M. Alfonso-Pérez, I. Benedicto, F. SánchezMadrid, R. González-Amaro, and M. Marazuela, "Increased circulating pro-inflammatory cytokines and Th17 lymphocytes in Hashimoto's thyroiditis," Journal of Clinical Endocrinology and Metabolism, vol. 95, no. 2, pp. 953-962, 2010.

[4] Y. Shi, H. Wang, Z. Su et al., "Differentiation imbalance of Th1/Th17 in peripheral blood mononuclear cells might contribute to pathogenesis of Hashimoto's thyroiditis," Scandinavian Journal of Immunology, vol. 72, no. 3, pp. 250-255, 2010.

[5] D. Li, W. Cai, R. Gu et al., "Th17 cell plays a role in the pathogenesis of Hashimoto's thyroiditis in patients," Clinical Immunology, vol. 149, pp. 411-420, 2013.

[6] T. Nanba, M. Watanabe, N. Inoue, and Y. Iwatani, "Increases of the Th1/Th2 cell ratio in severe Hashimoto's disease and in the proportion of Th17 cells in intractable Graves' disease," Thyroid, vol. 19, no. 5, pp. 495-501, 2009.

[7] Y. Liu, X. Tang, J. Tian et al., "Th17/Treg cells imbalance and GITRL profile in patients with Hashimoto's thyroiditis," International Journal of Molecular Sciences, vol. 15, no. 12, pp. 21674-21686, 2014.

[8] H. Xue, X. Yu, L. Ma et al., "The possible role of $\mathrm{CD}^{+} \mathrm{CD} 25^{\text {high }} \mathrm{Foxp}^{+} / \mathrm{CD} 4^{+} \mathrm{IL}^{-17 \mathrm{~A}^{+}}$cell imbalance in the autoimmunity of patients with Hashimoto thyroiditis," Endocrine, vol. 50, no. 3, pp. 665-673, 2015.

[9] R. Grenningloh, Y. K. Bok, and I.-C. Ho, "Ets-1, a functional cofactor of T-bet, is essential for Th1 inflammatory responses," Journal of Experimental Medicine, vol. 201, no. 4, pp. 615-626, 2005.

[10] H.-W. Tsao, T.-S. Tai, W. Tseng et al., "Ets-1 facilitates nuclear entry of NFAT proteins and their recruitment to the IL-2 promoter," Proceedings of the National Academy of Sciences of the United States of America, vol. 110, no. 39, pp. 15776-15781, 2013.

[11] E. Mouly, K. Chemin, H. V. Nguyen et al., "The Ets-1 transcription factor controls the development and function of natural regulatory T cells," Journal of Experimental Medicine, vol. 207, no. 10, pp. 2113-2125, 2010.

[12] L. Cimmino, G. A. Martins, J. Liao et al., "Blimp-1 attenuates Th1 differentiation by repression of ifng, tbx 21 , and bcl6 gene expression," Journal of Immunology, vol. 181, no. 4, pp. 23382347, 2008.

[13] G. A. Martins, L. Cimmino, J. Liao, E. Magnusdottir, and K. Calame, "Blimp-1 directly represses Il2 and the Il2 activator Fos, attenuating $\mathrm{T}$ cell proliferation and survival," Journal of Experimental Medicine, vol. 205, no. 9, pp. 1959-1965, 2008.

[14] E. Cretney, A. Xin, W. Shi et al., "The transcription factors Blimp-1 and IRF4 jointly control the differentiation and function of effector regulatory T cells," Nature Immunology, vol. 12, no. 4, pp. 304-311, 2011.
[15] E. V. Dang, J. Barbi, H.-Y. Yang et al., "Control of TH17/Treg balance by hypoxia-inducible factor 1," Cell, vol. 146, no. 5, pp. 772-784, 2011.

[16] M. Štefanić, S. Papić, M. Suver, L. Glavaš-Obrovac, and I. Karner, "Association of vitamin D receptor gene 3'-variants with Hashimoto's thyroiditis in the Croatian population," International Journal of Immunogenetics, vol. 35, no. 2, pp. 125-131, 2008.

[17] A. Böyum, "Separation of leukocytes from blood and bone marrow. Introduction," Scandinavian Journal of Clinical And Laboratory Investigation, Supplementum, vol. 97, article 7, 1968.

[18] P. Chomczynski and N. Sacchi, "Single-step method of RNA isolation by acid guanidinium thiocyanate-phenol-chloroform extraction," Analytical Biochemistry, vol. 162, no. 1, pp. 156-159, 1987.

[19] M. W. Pfaffl, "A new mathematical model for relative quantification in real-time RT-PCR," Nucleic Acids Research, vol. 29, no. 9, article e45, 2001.

[20] I. Horie, N. Abiru, H. Sakamoto, Y. Iwakura, and Y. Nagayama, "Induction of autoimmune thyroiditis by depletion of $\mathrm{CD} 4{ }^{+} \mathrm{CD} 25^{+}$regulatory $\mathrm{T}$ cells in thyroiditis-resistant IL-17, but not interferon- $\gamma$ receptor, knockout nonobese diabetic- $\mathrm{H} 2 \mathrm{~h} 4$ mice," Endocrinology, vol. 152, no. 11, pp. 4448-4454, 2011.

[21] S. Oh and E. S. Hwang, "The role of protein modifications of Tbet in cytokine production and differentiation of thelper cells," Journal of Immunology Research, vol. 2014, Article ID 589672, 7 pages, 2014.

[22] Q. Qin, P. Liu, L. Liu et al., "The increased but non-predominant expression of Th17- and Th1-specific cytokines in hashimoto's thyroiditis but not in graves' disease," Brazilian Journal of Medical and Biological Research, vol. 45, no. 12, pp. 1202-1208, 2012.

[23] G. Karanikas, M. Schuetz, K. Wahl et al., "Relation of antiTPO autoantibody titre and T-lymphocyte cytokine production patterns in Hashimoto's thyroiditis," Clinical Endocrinology, vol. 63, no. 2, pp. 191-196, 2005.

[24] A.-C. Gérard, M. Boucquey, M.-F. Van Den Hove, and I. M. Colin, "Expression of TPO and ThOXs in human thyrocytes is downregulated by IL- $1 \alpha / \mathrm{IFN}-\gamma$, an effect partially mediated by nitric oxide," American Journal of Physiology - Endocrinology and Metabolism, vol. 291, no. 2, pp. E242-E253, 2006.

[25] L. Marique, V. Van Regemorter, A.-C. Gérard et al., "The expression of dual oxidase, thyroid peroxidase, and caveolin-1 differs according to the type of immune response (TH1/TH2) involved in thyroid autoimmune disorders," Journal of Clinical Endocrinology and Metabolism, vol. 99, no. 5, pp. 1722-1732, 2014.

[26] H. W. Su, J. D. Bretz, E. Phelps et al., "A unique combination of inflammatory cytokines enhances apoptosis of thyroid follicular cells and transforms nondestructive to destructive thyroiditis in experimental autoimmune thyroiditis," Journal of Immunology, vol. 168, no. 5, pp. 2470-2474, 2002.

[27] M. Marazuela, M. A. García-López, N. Figueroa-Vega et al., "Regulatory T cells in human autoimmune thyroid disease," Journal of Clinical Endocrinology and Metabolism, vol. 91, no. 9, pp. 3639-3646, 2006.

[28] V. De Rosa, M. Galgani, A. Porcellini et al., "Glycolysis controls the induction of human regulatory $\mathrm{T}$ cells by modulating the expression of FOXP3 exon 2 splicing variants," Nature Immunology, vol. 16, no. 11, pp. 1174-1184, 2015.

[29] B. Kristensen, L. Hegedüs, H. O. Madsen, T. J. Smith, and C. H. Nielsen, "Altered balance between self-reactive T helper 
(Th)17 cells and Th10 cells and between full-length forkhead box protein 3 (FoxP3) and FoxP3 splice variants in Hashimoto's thyroiditis," Clinical and Experimental Immunology, vol. 180, no. 1, pp. 58-69, 2015.

[30] L. R. Ryder, A. Woetmann, H. O. Madsen et al., "Expression of full-length and splice forms of FoxP3 in rheumatoid arthritis," Scandinavian Journal of Rheumatology, vol. 39, no. 4, pp. 279286, 2010.

[31] H. Ban, A. Andoh, M. Shioya, A. Nishida, T. Tsujikawa, and Y. Fujiyama, "Increased number of FoxP3+CD4+ regulatory T cells in inflammatory bowel disease," Molecular Medicine Reports, vol. 1, no. 5, pp. 647-650, 2008.

[32] A. Nakano, M. Watanabe, T. Iida et al., "Apoptosis-induced decrease of intrathyroidal $\mathrm{CD} 4{ }^{+} \mathrm{CD} 25^{+}$regulatory $\mathrm{T}$ cells in autoimmune thyroid diseases," Thyroid, vol. 17, no. 1, pp. 25-31, 2007.

[33] C. Mao, S. Wang, Y. Xiao et al., "Impairment of regulatory capacity of CD4+CD25+ regulatory T cells mediated by dendritic cell polarization and hyperthyroidism in Graves' disease," Journal of Immunology, vol. 186, no. 8, pp. 4734-4743, 2011.

[34] J. M. R. van Amelsfort, K. M. G. Jacobs, J. W. J. Bijlsma, F. P. J. G. Lafeber, and L. S. Taams, "CD4+CD25+ regulatory T cells in rheumatoid arthritis: differences in the presence, phenotype, and function between peripheral blood and synovial fluid," Arthritis and Rheumatism, vol. 50, no. 9, pp. 2775-2785, 2004.

[35] R. González-Amaro and M. Marazuela, "T regulatory (Treg) and T helper 17 (Th17) lymphocytes in thyroid autoimmunity," Endocrine, vol. 52, no. 1, pp. 30-38, 2016.

[36] M. Veldhoen, R. J. Hocking, C. J. Atkins, R. M. Locksley, and B. Stockinger, "TGF $\beta$ in the context of an inflammatory cytokine milieu supports de novo differentiation of IL-17-producing T cells," Immunity, vol. 24, no. 2, pp. 179-189, 2006.

[37] L. Li and V. A. Boussiotis, "Molecular and functional heterogeneity of T regulatory cells," Clinical Immunology, vol. 141, no. 3, pp. 244-252, 2011.

[38] M. A. Koch, G. Tucker-Heard, N. R. Perdue, J. R. Killebrew, K. B. Urdahl, and D. J. Campbell, "The transcription factor T-bet controls regulatory $\mathrm{T}$ cell homeostasis and function during type 1 inflammation," Nature Immunology, vol. 10, no. 6, pp. 595-602, 2009.

[39] F. Yu, S. Sharma, J. Edwards, L. Feigenbaum, and J. Zhu, "Dynamic expression of transcription factors T-bet and GATA3 by regulatory T cells maintains immunotolerance," Nature Immunology, vol. 16, no. 2, pp. 197-206, 2015.

[40] L. Tian, J. A. Altin, L. E. Makaroff et al., "Foxp3+ regulatory T cells exert asymmetric control over murine helper responses by inducing Th2 cell apoptosis," Blood, vol. 118, no. 7, pp. 1845-1853, 2011.

[41] J. Hua, S. P. Davis, J. A. Hill, and T. Yamagata, "Diverse gene expression in human Regulatory $\mathrm{T}$ cell subsets uncovers connection between regulatory $\mathrm{T}$ cell genes and suppressive function," Journal of Immunology, vol. 195, no. 8, pp. 3642-3653, 2015.

[42] X. Li, Y. Liang, M. Leblanc, C. Benner, and Y. Zheng, "Function of a foxp3 cis-element in protecting regulatory T cell identity," Cell, vol. 158, no. 4, pp. 734-748, 2014.

[43] M. H. Lin, L. T. Yeh, S. J. Chen et al., "T cell-specific BLIMP-1 deficiency exacerbates experimental autoimmune encephalomyelitis in nonobese diabetic mice by increasing Th1 and Th17 cells," Clinical Immunology, vol. 151, no. 2, pp. 101-113, 2014.
[44] J. Moisan, R. Grenningloh, E. Bettelli, M. Oukka, and I.-C. Ho, "Ets-1 is a negative regulator of Th17 differentiation," Journal of Experimental Medicine, vol. 204, no. 12, pp. 2825-2835, 2007.

[45] J. K. Polansky, L. Schreiber, C. Thelemann et al., "Methylation matters: Binding of Ets-1 to the demethylated Foxp3 gene contributes to the stabilization of Foxp3 expression in regulatory $\mathrm{T}$ cells," Journal of Molecular Medicine, vol. 88, no. 10, pp. 10291040, 2010.

[46] E. Cretney, A. Xin, W. Shi et al., "The transcription factors Blimp-1 and IRF4 jointly control the differentiation and function of effector regulatory T cells," Nature Immunology, vol. 12, no. 4, pp. 304-312, 2011. 


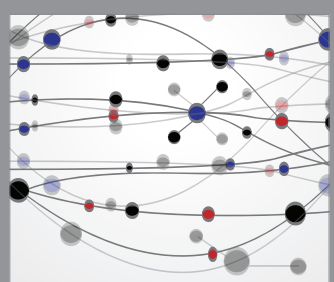

The Scientific World Journal
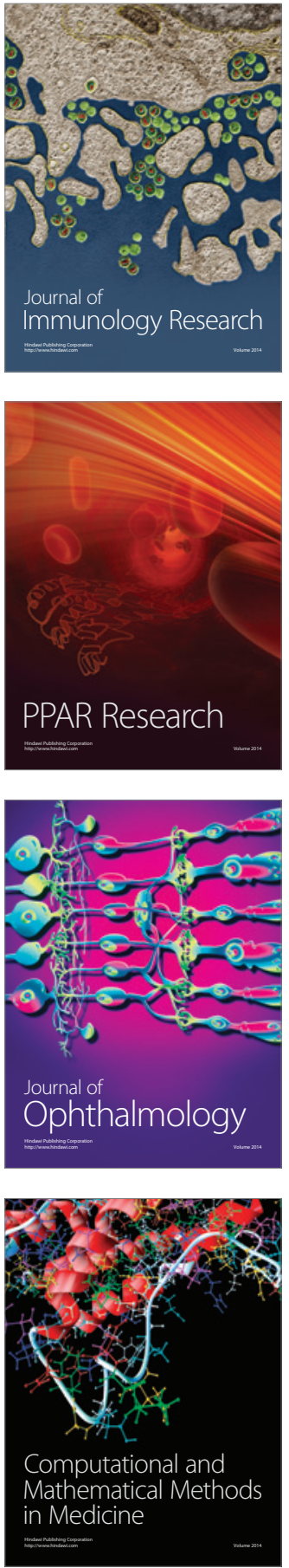

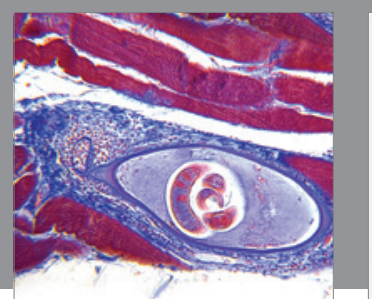

Gastroenterology Research and Practice

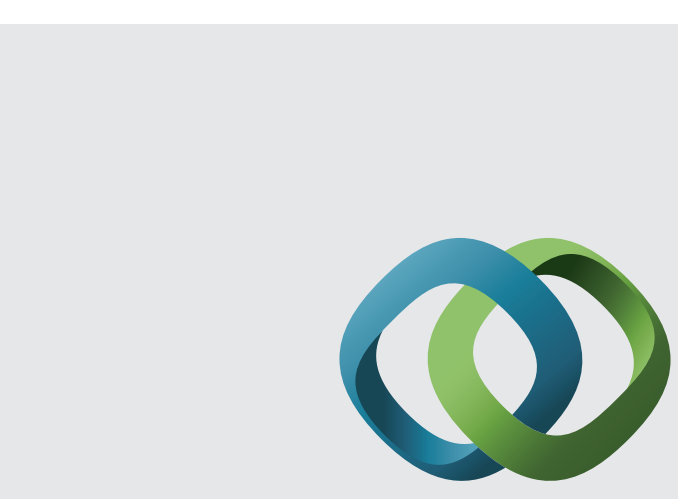

\section{Hindawi}

Submit your manuscripts at

http://www.hindawi.com
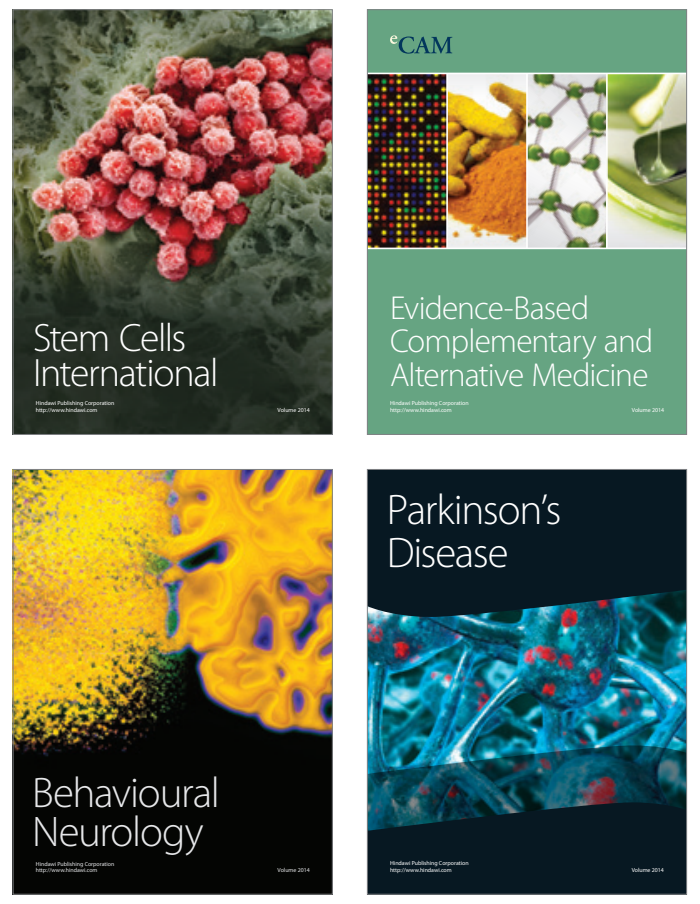
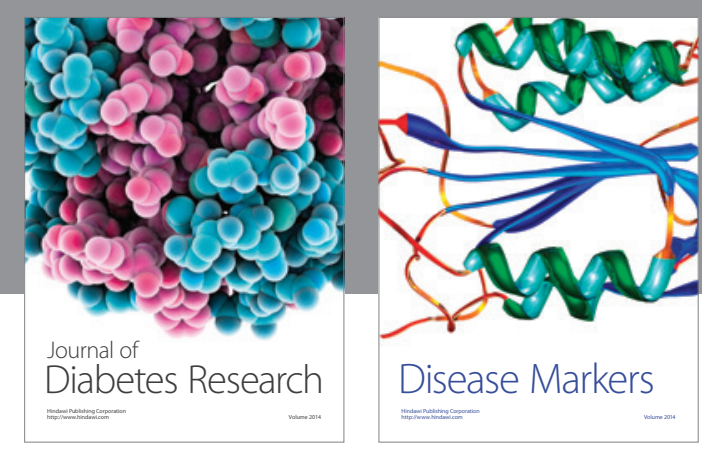

Disease Markers
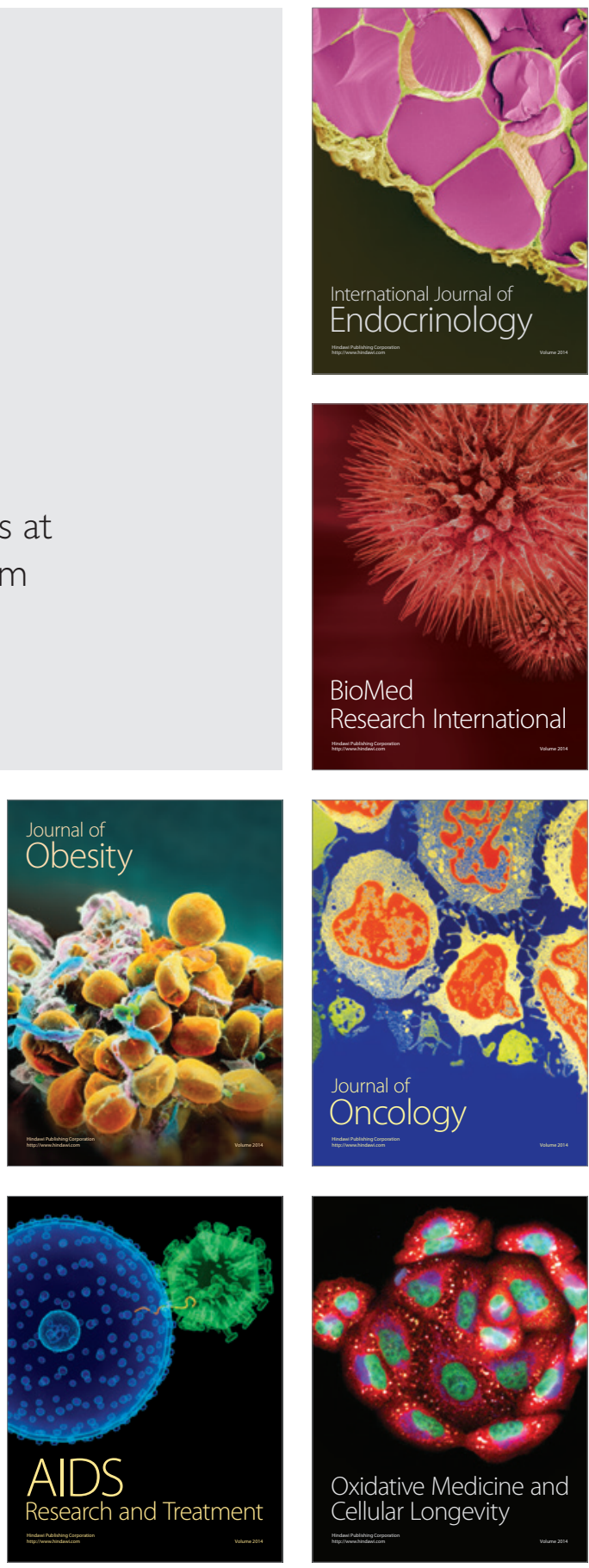